\title{
Создание и деятельность частной бесплатной женской профессиональной школы А.А. Машковцевой на территории Таврической губернии в конце XIX - начале XX вв.
}

\author{
В.А. Масленникова \\ Таврическая академия Крымского федерального университета имени Вернадского, \\ Россия, 295007, Симферополь, просп. Вернадского, 20 \\ E-mail: Ms.Valeris@bk.ru
}

\begin{abstract}
Аннотация. В селах Российской империи конца XIX в. у девочек, живущих в больших и в бедных семьях, зачастую не было возможности получить образование. Именно для помощи неимущим была открыта бесплатная женская профессиональная школа А.А. Машковцевой. В статье анализируются источники, которые затрагивали вопросы гендерного неравноправия в образовании на территории Таврической губернии, обоснование необходимости женского образования в целом. Информация о финансированиии и функционировании частной бесплатной женской профессиональной школы А.А. Машковцевой, представленная в статье, позволяет многосторонне оценить деятельность школы на территории Таврической губернии. Автор уделяет внимание поэтапному становлению школы, происходившему наряду с постепенным расширением курсов. В статье указывается, что данное образовательное учреждение было оценено населением как реальная поддержка жителей губернии. В статье дана оценка деятельности школы А.А. Машковцевой.
\end{abstract}

Ключевые слова: женщины, образование, Таврическая губерния, воспитание.

Благодарности: работа выполнена при поддержке А.А Задерейчук, к. и. н. Крымского федерального университета имени Вернадского.

Для цитирования: Масленникова В.А. 2020. Создание и деятельность частной бесплатной женской профессиональной школы А.А. Машковцевой на территории Таврической губернии в конце XIX - начале XX вв. Via in tempore. История. Политология, 47 (4): 803-810. DOI: $10.18413 / 2687-0967-2020-47-4-803-810$.

\section{Creation and activity of a private free female professional school of A.A. Mashkovtseva on the territory of the Tavricheskaya province in the late $X I X$ - early XX centuries}

\author{
Valeria A. Maslennikova \\ V. A. Taurida Academy of the Vernadsky Crimean Federal University, \\ 20 Ave. Vernadsky, Simferopol, 295007, Russia \\ E-mail: Ms.Valeris@bk.ru
}

\begin{abstract}
In the villages of the Russian Empire at the end of the XIX century girls living in large and poor families often did not have access to education due to its costliness. For such cases (to help the poor) the free female professional school of A.A. Mashkovtseva was opened. The article analyzes the sources that touch upon a subject of gender inequality in education on the territory of the Tauride province and the substantiation of the need for female education in general. The information on the financing and functioning of the private free female professional school of A.A. Mashkovtseva, provided in the article, allows us to esteem the school's activities on the territory of the Taurida province from all angles. The author pays attention to the gradual formation of the school, which took place along with the gradual
\end{abstract}


expansion of courses. The article indicates that this educational institution was assessed by the population as a real support of the inhabitants of the province.

Keywords: women, education, Tauride province, education.

Acknowledgements: This work was supported by A.A. Zadereichuk, Candidate of Historical Sciences, Vernadsky Crimean Federal University.

For citation: Maslennikova V.A. 2020. Creation and activity of a private free female professional school of A.A. Mashkovtseva on the territory of the Tavricheskaya province in the late XIX - early XX centuries. Via in tempore. History and political science, 47 (4): 803-810 (in Russian). DOI: $10.18413 / 2687-0967-2020-47-4-803-810$.

\section{Введение}

Повышенное внимание к женскому образованию в Российской империи во многом спровоцировано осознанием «женского вопроса», распространившегося с 60-х гг. XIX вв. Проблемы доступности и распространения женского образования, борьбу с которыми объявляли выдающиеся умы Российской империи, и по сей день волнуют исследователей. Вовлечение женского населения в трудовые отношения повлияло на доступность профессиональной подготовки, расширив сеть женских образовательных учреждений. Важность существования ремесленных школ не подвергалась сомнению, ведь овладевая ремеслом, девушки Таврической губернии обеспечивали свои потребности.

Данное исследование призвано систематизировать, расширить и дополнить историю частной бесплатной женской профессиональной школы А.А. Машковцевой как одного из важных центров обучения девушек на территории Таврической губернии. В связи с заданной целью анализируется историческая литература и источники, касающиеся ремесленного образования в Таврической губернии. Рассматриваются основные источники финансирования школы, благодаря которым появляется возможность говорить о признании школы земством. Раскрывается вопрос о поэтапном расширении школы и курсов, читавшихся ученицам. В исследовании продемонстрирована роль школы в жизни учениц посредством анализа отчетов о приходах и расходах, которые позволяют говорить о финансовой поддержке неимущих учащихся.

\section{Объекты и методы исследования}

Методологической основной исследования являлось применение диалектического и системного подхода. При написании данной работы использовались общие методы исторического исследования: использование многочисленных разнообразных источников и их анализ, историческое описание и историко-сравнительный анализ.

Прежде всего стоит указать на то, что основной пласт информации, касающийся финансирования, становления школы, педагогического состава, расширения образовательного процесса располагался в делопроизводственных источниках земского учреждения, а также в памятных книгах Таврической губернии. Источниковую базу исследования дополняют документы Российского государственного исторического архива, периодические издания Таврической губернии.

Объемный труд, изданный благодаря съезду русских деятелей по техническому и профессиональному образованию, рассматривал множество положений, касающихся различных вопросов о женских профессиональных училищах: от обзора необходимых предметов, до вопроса о развитии «чувства изящного» в ученицах школ [Съезд русских деятелей, 1890]. М.В. Кечеджи-Шаповалов указывал на тот факт, что определенные сословия не могли прийти к общему решению вопроса о женском образовании, таким образом, поднимался вопрос о существовании гендерного неравноправия в получении образования. 
Он продемонстрировал, что в некоторых случаях «желание сословия находило препятствие по воле одного», - так, Таврическое дворянство в большинстве (126 голосов против 39) постановило вносить средства на Симферопольскую женскую гимназию, однако постановление два года не исполнялось по причине несогласия губернского предводителя дворянства, который считал, что женщинам не следует «излишне образовываться» [Кечеджи-Шаповалов, 1902, с. 135].

Одной из исследовательниц, которой принадлежит монументальный труд об истории женского образования в России, можно назвать Е.О. Лихачеву. В ее научном труде содержится множество материалов с комментариями автора за период с 1856 по 1880 гг. [Лихачева, 1901]. В.М. Хвостов тесно связывал женское образование с обретением обширных прав женщинами России. Так же автор, ссылаясь на нравственную философию, указал на то, что умственное развитие - не только право, но и обязанность женщины [Хвостов, 1905, с. 36]. К.В. Ельницкий освещает вопрос о значении педагогического образования [Ельницкий, 1912].

Исторический очерк деятельности школы А.А. Машковцевой вносит ясность в некоторые аспекты существования частной бесплатной женской профессиональной школы [Симферопольская женская, 1916]. В постановлениях Симферопольского уездного земского собрания раскрываются вопросы о финансировании школы, представлены отчеты о приходах и расходах частной бесплатной профессиональной женской школы. Следует указать на то, что периодически публиковались доклады о школе А.А. Машковцевой, в которых были произведены анализы существовавших в ней предметов, о проходивших экзаменах. Также стоит учесть, что в определенных отчетах было указано, какой слой населения получал образование в стенах частной профессиональной женской школы, и обосновывалось получение малоимущими ученицами дотаций в виде обуви, одежды и еды [Постановления, 1912, Памятная книжка, 1914. с. 55-57].

Информация о педагогическом составе содержится в Памятных книгах Таврической губернии [Адрес-календарь, 1913, с. 42; Памятная книжка Таврической губернии, с. 45]. Следует сказать, что педагогический коллектив школы был довольно велик по сравнению с другими школами Таврической губернии. В преподавательском составе значились законоучитель, учителя естествознания, искусств, пения, счетоводства, арифметики, также в школе числились 8 учительниц рукоделия. Текучесть кадров была минимальна.

В постреволюционной России отсутствуют исследователи, интересовавшиеся судьбой школы А.А. Машковцевой. Современные ученые лишь фрагментарно упоминают eе, так Д.А. Громова, анализируя профессиональный статус народной учительницы, указала на тот факт, что ученицы оставались в роли преподавательниц в своих же учебных заведениях, сославшись на частную бесплатную женскую профессиональную школу А.А. Машковцевой [Громова, 2016, с. 93]. Ученые Н.Ф. Дундук и Л.Л. Кузьмина, исследуя профессиональные учебные заведения Таврической губернии XIX - начала XX вв., указывают на школу А.А. Машковцевой как на самое известное ремесленное учебное заведение в Таврической губернии [Дундук, Кузьмина].

\section{Результаты и их обсуждение}

Частная бесплатная женская профессиональная школа была открыта под именем Анны Аркадьевны Машковцевой, которая до этого занималась в бесплатной школе грамоты г-жи Урлашевой в г. Симферополь. Стоит отметить, что А.А. Машковцева также являлась вольнослушательницей на Санкт-Петербургских высших женских курсах в 1893-1894 гг. [Н.А. Ветвеницкая, 1895, с. 51]. Вернувшись из Санкт-Петербурга, участвовала в спонсировании бесплатной школы грамотности г-жи Урлашевой, а в 1895 г. основала свою школу [Постановления, 1896, с. 60].

Стоит указать на тот факт, что финансирование школа получала от частных лиц, из общественных и казенных средств, как, например, от Министерства народного просвеще- 
ния, Симферопольского городского управления [Постановления 6-го ноября 1909 года, 1910. с. 200]. Большую часть средств, вкладывала учредительница школы А.А. Машковцева [Постановления 6-го ноября 1909 года, 1910, с. 47-48]. В 1902 г. учредительница подала ходатайство о софинансировании школы Симферопольским земством в связи с растущими расходами, с которыми она столкнулась при введении новых отраслей профессионального обучения [Постановления, 1903, с. 251]. После ходатайства А.А. Машковцевой о пособии Уездное Земское собрание, приняв во внимание, что в заведении обучались дети беднейших жителей, удовлетворило ее просьбу [Постановления, 1903, с. 253]. Помимо этого, в школе устраивались вечера и выставки, позволяющие получать заказы и реализовать изготовленную ученицами продукцию [Отчет, 1909, с. 3; Происшествия, 1911, с. 3].

Возрастной состав поступавших в первый класс был практически однороден - девочкам было 12-14 лет. По наблюдениям педагогов, дети более младшего возраста с трудом усваивали материал, также у них отсутствовала усидчивость и сосредоточенность на предмете [Иванникова, 2016, с. 60].

Первоначально школа была открыта с тремя классами. Программа общеобразовательных предметов равнялась приблизительно программе двухклассных министерских школ. Прием в школу производился дважды в год - в конце мая и в конце августа. В I класс школы принимались по конкурсному отбору девочки по окончанию городских, земских, церковно-приходских школ с 4-х годичным курсом либо с соответствующей домашней подготовкой.

В 1899 г. был открыт IV класс, в 1904 г. - V. Курс общеобразовательных предметов к тому времени расширился до программ испытания на звание начальной учительницы. Те, кто желал получить данное звание, отдельно сдавали экзамен при гимназии. Так, в профессиональной школе девушки проходили весьма обширную практику по шитью, кройке и вышивке. С 1908 г. школа ввела специальность вязание, а по общеобразовательным предметам программу 4-х классов женской гимназии, постепенно пополнявшуюся следующими предметами: естествоведением с кратким курсом физики, общим курсом гигиены, куда входили анатомия, физиология, краткой геометрией, кратким очерком русской литературы, курсом рисования и черчения. В V классе были введены счетоводство, товароведение, школьная и ремесленная гигиена, педагогика, методика рукоделия, рисование, литература. Светское пение проходили во всех классах, духовное - с отдельными классами. Гимнастику проводили в первых трех классах. C 1912 г. был открыт VI класс с усиленными практическими занятиями для совершенствования навыков учениц. Здесь продолжалось изучение русской литературы, педагогики, рисования и черчения.

Религиозно-нравственному обучению уделяли особое внимание. Перед началом урока и в конце совершалась общая молитва. Утренняя молитва сопровождалась чтением Евангелия на русском и славянском языках. Ученицы в обязательном порядке посещали воскресные и праздничные службы. За 20 лет существования школы серьезных нарушений не было выявлено. Единственное, как указывали педагоги, что повторялось из года в год, - присвоение чужой собственности. Это явление наблюдалось в школе ежегодно и объяснялось главным образом с преобладанием малоимущих обучающихся. Присвоение чужой собственности, как считало руководство школы, в большинстве случаев не указывало на испорченность учениц, а являлось следствием нужды. Так, девушки заимствовали друг у друга завтраки, книги и прочее. Руководство школы, выдавая бесплатно все эти вещи неимущим, уменьшали вероятность воровства на территории образовательного учреждения.

При открытии школы в нее поступило 7 учениц, из года в год количество желающих обучаться в школе увеличивалось, кроме 1914 г. - военное время отразилось на населении. В газетах давали объявления о датах приемных экзаменов в профессиональной женской школе А.А. Машковцевой [Происшествия, Южные, 1909, с. 3]. На вступительные экзамены 
являлось в 2-3 раза больше, чем школа могла принять, что свидетельствовало о чрезвычайной востребованности профессионального образования среди женского населения.

Окончившие курс девушки получали свидетельства об окончании школы и свидетельство из Ремесленной управы на звание подмастерья по платью и белью. В феврале 1908 г. школа получила право самим производить испытания учащихся и выдавать свидетельства на звания учительниц рукоделия в женских гимназиях и прогимназиях. К 1912 г. из 125 лиц, окончивших школу А.А. Машковцевой, 50 работали как мастерицы в различных местах, 23 девушки устроились учительницами, другие же устраивались в ясли, библиотеки, уходили в гувернантки [РГИА Ф. 1278. Оп. 6. Д. 185, с. 4] ${ }^{56}$.

Для неимущего класса Профессиональная школа являлась важной ступенью для самостоятельной жизни, ведь именно школа давала возможность девушкам зарабатывать себе на пропитание. При школе имелась ученическая касса, созданная, как упоминалось педагогами, для развития сознания в ученицах пользы своевременно оказанной взаимной помощи. Средства кассы составляли 5 \% от заработка мастерских и пожертвований учащихся. Пособия выдавались в случае крайней нужды: болезни, потери работы родителями. Некоторые ученицы прибегали в такой помощи довольно часто, однако большая часть пользовала эти средства в крайних случаях. Можно говорить о том, что взаимопомощь в основном оказывалась ученицам более старшего возраста, в среднем в размере 5 руб. в месяц [Симферопольское уездное земское, 1912, с. 55-57].

Школа А.А. Машковцевой в сознании малоимущего населения являлась «рукой помощи», ведь в целом по губернии образование было на платной основе. Средняя цена для обучения составляла в городских училищах 27 руб. 39 коп., в селах - 20 руб. 94 коп. в год, эти суммы были довольно ощутимы для местного населения [Постановления XXXII-го..., 1898, с. 226].

Руководство школы учитывало, что значительный процент обучаемых детей из неимущего класса, поэтому нуждающимся ученицам выдавали башмаки, галоши, материалы на форменное платье и горячий обед. В 1911 г. 30 учениц бесплатно обедали, помимо этого в течение всего года было выдано 35 пар башмаков и 32 пары галош [Симферопольское уездное земское, 1912, с. 55-57]. Из отчета о приходах и расходах школы следует, что требования неимущих учениц на обувь и одежду постоянно увеличивались, как и количество голодающих, поэтому субсидирование завтраков и одежды постепенно увеличивалось [Постановления 6-го ноября 1909 года, 1910, с. 48].

Следует учесть, что судьба школы на 1917 год остается неизвестной, скорее всего, из-за недостатка финансирования частная бесплатная женская профессиональная школа закрыла свои двери для девушек, желающих обучаться ремеслам. Так, по данным отчета Таврической дирекции о состоянии училищ за 1916 г. видно, что в Таврической губернии осталось 5 женских профессиональных школ [РГИА Ф. 733. Оп. 205. Д. 3229, с. 58] ${ }^{57}$. В целом количественные показатели образовательных учреждений для девушек с 1911 г. свидетельствуют о некотором сокращении профессиональных школ [Дундук, Кузьмина].

\section{Заключение}

Подводя итог, можно говорить о том, что частная бесплатная женская профессиональная школа А.А. Машковцевой, открывшая свои двери 19 февраля 1896 г. в г. Симферополь, пришла на помощь способным девушкам, не имевшим достаточного материального обеспечения для учебы. В целом на территории Таврической губернии существовало гендерное неравенство в доступности образования. В мальчиков охотнее вкладывали средства, ведь мужчина на ментальном уровне воспринимался как добытчик, способный поддержать семью в материальном плане. А вот девушек, имевших образование, было

\footnotetext{
${ }^{56}$ РГИА Ф. 1278. Оп. 6. Д. 185. Об отпуске из казны пособий.

${ }^{57}$ РГИА Ф. 733. Оп. 205. Д. 3229 Таврической дирекции о состоянии училищ за 1916 г.
} 
меньше, как гласила поговорка - «дочка - отрезанный ломоть» [Полятус, 1909, с. 2]. Считалось, что девушка быстрее покидает отеческий дом, выходя замуж, именно поэтому вложение в ее образование было лишено смысла для большей части населения. Финансирование школы позволяло содержать малоимущих учениц, им выделяли одежду, обувь, деньги на завтраки. Имеющаяся при школе касса гарантировала поддержку ученицам, попавшим в тяжелую жизненную ситуацию.

Таким образом, представляется возможным говорить о том, что школа взяла на себя обязательства по воспитанию девушек из малоимущих семей, давала им возможность приобрести практические знания, которые обеспечивали им их существование.

\section{Благодарности}

Автор выражает глубокую благодарность научному руководителю, кандидату исторических наук Алле Анатольевне Задерейчук.

\section{Список источников}

1. Российский государственный исторический архив (РГИА) Ф. 1278. Оп. 6. Д. 185. Об отпуске из казны пособий.

2. РГИА Ф. 733. Оп. 205. Д. 3229 Таврической дирекции о состоянии училищ за 1916 г.

\section{Список литературы}

1. Адрес-календарь. 1913. Справочная книга Таврической губернии на 1913. Изд. тавр. губ. правления. Симферополь, Таврическ. Губернск. Типография, 423.

2. Громова Д.А. 2016. Социальный статус женщин-учителей народных училищ в России в конце XIX - начале XX веков: по материалам Таврической губернии. Диссертация ... кандидата исторических наук. М., 198.

3. Дундук Н.Ф., Кузьмина Л.Л. Профессиональные заведения Таврической губернии в XIX - нач. XX в. Статья. URL: https://core.ac.uk/download/pdf/38417592.pdf (дата обращения: 23 июня 2020).

4. Ельницкий К.В. Значение педагогического образования для женщин как воспитательниц и учительниц детей. Киев, тип. акц. о-ва Н.Т. Корчак-Новицкого, 8.

5. Иванникова М.В. 2016. Из истории ремесленного образования в Крыму. Психология и педагогика в образовательной и научной среде: Международное научное периодическое издание по итогам Международной научно-практической конференции (17 ноября 2016, г. Сургут). Стерлитамак: АМИ, 60.

6. Кечеджи-Шаповалов М.В. 1902. Женское движение в России и заграницей. СПб., тип. Спб. о-ва печ. дела в России Е. Евдокимов, 210.

7. Лихачева Е.О. 1901. Материалы для истории женского образования в России. СПб., Тип. М.М. Стасюлевича, 647.

8. Отчет. 1909. Южные ведомости. 39: 3.

9. Памятная книжка Таврической губернии на 1914 год. Симферополь, Таврическ. Губернск. Типография, 1914, 789.

10. Петербургские высшие женские курсы. Памятная книжка окончивших курс на Петербургских высших женских курсах. 1882-1889 г., 1893-1894 г. СПб., 1895, 112.

11. Полятус С. 1909. Речи по случаю семейных тождеств. Крымский шут. $28: 2$.

12. Постановления XXXII-го очередного Симферопольского уездного земского собрания 1897 года и экстренных собраний 16-го декабря 1897 г. и 22-го января 1898 г. с приложениями. Симферополь, Губ. Тип., 1898, 416.

13. Постановления Симферопольского уездного земского собрания 44 очередной сессии 1909 года и чрезвычайных... 6-го ноября 1909 года, 17-го января и 23 марта 1910 г.: С прил. докладов и отчетов Управы. Симферополь, 1910, 615.

14. Постановления Симферопольского уездного земского собрания XXXVII очередной сессии 1902 года: С прил. докладов и отчетов Управы. Симферополь, 1903, 515.

15. Постановления Симферопольского уездного земского собрания. С прил. докладов и отчетов Управы. Симферополь, 1896, 432. 
16. Постановления Симферопольского уездного земского собрания. С прил. докладов и отчетов Управы. Симферополь, 1912, 750.

17. Происшествия. 1909. Южные ведомости. 110: 3.

18. Происшествия. 1911. Южные ведомости. 36: 3.

19. Симферопольская женская профессиональная школа А.А. Машковцевой. Частная бесплатная женская профессиональная школа А.А. Машковцевой: Крат. очерк деятельности и состояние ее за двадцать лет существования (с 19 февр. 1896 г.). Симферополь, 1916, 67.

20. Симферопольское уездное земское собрание. Постановления Симферопольского уездного земского собрания...: С прил. докладов и отчетов Управы. Симферополь, 1867-1915. 21-27. 46 очередной сессии 1911 года и чрезвычайных... 10 и 11 декабря 1911 года, 31 марта и 31 июля 1912 г. 1912, 750.

21. Съезд русских деятелей по техническому и профессиональному образованию. Труды Съезда русских деятелей по техническому и профессиональному образованию в России. СПБ., Изд. под гл. ред. секретаря Съезда В.И. Срезневского, 1890, 458.

22. Хвостов В.М. 1905. Женщина накануне новой эпохи: два этюда по женскому вопросу. М., Тип. Г. Лисснера и Д. Совко, 101.

\section{References}

1. Adres-kalendar'. 1913. Spravochnaya kniga Tavricheskoy gubernii na 1913 [Address calendar. Reference book of the Tauride province for 1913]. Izd. tavr. gub. pravleniya. Simferopol', Tavrichesk. Gubernsk. Tipografiya, 423 (in Russian).

2. Gromova D.A. 2016. Sotsial'nyy status zhenshchin-uchiteley narodnykh uchilishch v Rossii v kontse XIX - nachale XX vekov: po materialam Tavricheskoy gubernii [Social status of women teachers of public schools in Russia in the late XIX - early XX centuries: based on the materials of the Tauride province]. Dissertatsiya ... kandidata istoricheskikh nauk. M., 198 (in Russian).

3. Dunduk N.F., Kuzmina L.L. Professional institutions of the Tauride province in the XIX early. XX century Article. URL: https://core.ac.uk/download/pdf/38417592.pdf (accessed June 23, 2020).

4. El'nitskiy K.V. Znachenie pedagogicheskogo obrazovaniya dlya zhenshchin, kak vospitatel'nits i uchitel'nits detey [The importance of pedagogical education for women as educators and teachers of children]. Kiev, tip. akts. o-va N.T. Korchak-Novitskogo, 8 (in Russian).

5. Ivannikova M.V. 2016. Iz istorii remeslennogo obrazovaniya v Krymu [From the history of craft education in the Crimea]. Psikhologiya i pedagogika v obrazovatel'noy i nauchnoy srede: Mezhdunarodnoe nauchnoe periodiche-skoe izdanie po itogam Mezhdunarodnoy nauchno-prakticheskoy konferentsii [Psychology and pedagogy in the educational and scientific environment: International scientific periodical based on the results of the International Scientific Practical Conference] (17 noyabrya 2016, g. Surgut). Sterlitamak: AMI, 60 (in Russian).

6. Kechedzhi-Shapovalov M.V. 1902. Zhenskoe dvizhenie v Rossii i zagranitsey [Women's movement in Russia and abroad]. SPb., tip. Spb. o-va pech. dela v Rossii E. Evdokimov, 210 (in Russian).

7. Likhacheva E.O. 1901. Materialy dlya istorii zhenskogo obrazovaniya v Rossii [Materials for the history of women's education in Russia]. SPb., Tip. M.M. Stasyulevicha, 647 (in Russian).

8. Otchet [Report]. 1909. Yuzhnye vedomosti. 39: 3 (in Russian).

9. Pamyatnaya knizhka Tavricheskoy gubernii na 1914 god [Memorial book of the Tauride province for 1914]. Simferopol', Tavrichesk. Gubernsk. Tipografiya, 1914, 789 (in Russian).

10. Peterburgskie vysshie zhenskie kursy. Pamyatnaya knizhka okonchivshikh kurs na Peterburgskikh vysshikh zhenskikh kursakh. 1882-1889 g., 1893-1894 g. [Petersburg Higher Women's Courses. Memorial book of those who graduated from the course at the St. Petersburg Higher Women's Courses. 1882-1889, 1893-1894] SPb., 1895, 112 (in Russian).

11. Polyatus S. 1909. Rechi po sluchayu semeynykh tozhdestv [Speeches on the occasion of family identities]. Krymskiy shut. 28: 2 (in Russian).

12. Postanovleniya XXXII-go ocherednogo Simferopol'skogo uezdnogo zemskogo sobraniya 1897 goda i ekstrennykh sobraniy 16-go dekabrya 1897 g. i 22-go yanvarya 1898 g. s prilozheniyami [Resolutions of the XXXII regular Simferopol district zemstvo assembly of 1897 and emergency meetings of December 16, 1897 and January 22, 1898 with annexes]. Simferopol', Gub. Tip., 1898, 416 (in Russian).

13. Postanovleniya Simferopol'skogo uezdnogo zemskogo sobraniya 44 ocherednoy sessii 1909 goda i chrezvychaynykh... 6-go noyabrya 1909 goda, 17-go yanvarya i 23 marta 1910 g.: S pril. 
dokladov i otchetov Upravy [Resolutions of the Simferopol District Zemstvo Assembly of the 44th regular session of 1909 and extraordinary... November 6, 1909, January 17 and March 23, 1910: From attached reports and reports of the Office]. Simferopol', 1910, 615 (in Russian).

14. Postanovleniya Simferopol'skogo uezdnogo zemskogo sobraniya XXXVII ocherednoy sessii 1902 goda: S pril. dokladov i otchetov Upravy [Resolutions of the Simferopol District Zemstvo Assembly XXXVII regular session of 1902: From attached reports and reports of the Office]. Simferopol', 1903, 515 (in Russian).

15. Postanovleniya Simferopol'skogo uezdnogo zemskogo sobraniya. S pril. dokladov i otchetov Upravy [Resolutions of the Simferopol District Zemstvo Assembly. With the attached reports and reports of the Office]. Simferopol', 1896, 432 (in Russian).

16. Postanovleniya Simferopol'skogo uezdnogo zemskogo sobraniya. S pril. dokladov i otchetov Upravy [Resolutions of the Simferopol District Zemstvo Assembly. With the attached reports and reports of the Office]. Simferopol', 1912, 750 (in Russian).

17. Proisshestviya [Incidents]. 1909. Yuzhnye vedomosti. 110: 3 (in Russian).

18. Proisshestviya [Incidents]. 1911. Yuzhnye vedomosti. 36: 3 (in Russian).

19. Simferopol'skaya zhenskaya professional'naya shkola A.A. Mashkovtsevoy. Chastnaya besplatnaya zhenskaya professional'naya shkola A.A. Mashkovtsevoy: Krat. ocherk deyatel'nosti i sostoyanie ee za dvadtsat' let sushchestvovaniya (s 19 fevr. 1896 g.) [Simferopol Women's Professional School A.A. Mashkovtseva. Private free female professional school A.A. Mashkovtseva: Krat. an outline of the activity and its state over twenty years of existence (from February 19. 1896)]. Simferopol', 1916, 67 (in Russian).

20. Simferopol'skoe uezdnoe zemskoe sobranie. Postanovleniya Simferopol'skogo uezdnogo zemskogo sobraniya...: S pril. dokladov i otchetov Upravy [Simferopol district zemstvo assembly. Resolutions of the Simferopol District Zemstvo Assembly...: From attached reports and reports of the Office]. Simferopol', 1867-1915. 21-27. 46 ocherednoy sessii 1911 goda i chrezvychaynykh... 10 i 11 dekabrya 1911 goda, 31 marta i 31 iyulya 1912 g. 1912, 750 (in Russian).

21. S"ezd russkikh deyateley po tekhnicheskomu i professional'nomu obrazovaniyu. Trudy S"ezda russkikh deyateley po tekhnicheskomu i professional'nomu obrazovaniyu v Rossii [Congress of Russian Figures on Technical and Vocational Education. Proceedings of the Congress of Russian Figures on Technical and Vocational Education in Russia]. SPB., Izd. pod gl. red. sekretarya S"ezda V.I. Sreznevskogo, 1890, 458 (in Russian).

22. Khvostov V.M. 1905. Zhenshchina nakanune novoy epokhi: dva etyuda po zhenskomu voprosu [Woman on the eve of a new era: two studies on the female issue]. M., Tip. G. Lissnera i D. Sovko, 101 (in Russian).

\section{ИНФОРМАЦИЯ ОБ АВТОРЕ}

Масленникова Валерия Андреевна, аспирант кафедры истории России Таврической академии Крымского федерального университета имени В.И. Вернадского г. Симферополь, Россия

\section{INFORMATION ABOUT THE AUTHOR}

Maslennikova Valeria Andreevna, $\mathrm{Ph}$. D. student of the Department of Russian History of the Tauride Academy of the Crimean Federal University named after V.I. Vernadsky, Simferopol, Russia 